\title{
Evaluating pulmonary function, aerobic capacity, and pediatric quality of life following a 10 -week aerobic exercise training in school-aged asthmatics: a randomized controlled trial
}

This article was published in the following Dove Press journal:

Patient Preference and Adherence

\author{
Walid K Abdelbasset ${ }^{1,2}$ \\ Saud F Alsubaie' \\ Sayed A Tantawy 3 \\ Tamer I Abo Elyazed ${ }^{4}$ \\ Dalia M Kamel ${ }^{3,5}$ \\ 'Department of Physical Therapy \\ and Health Rehabilitation, College \\ of Applied Medical Sciences, Prince \\ Sattam Bin Abdulaziz University, \\ Alkharj, Saudi Arabia; ${ }^{2}$ Department \\ of Physical Therapy, Kasr Al-Aini \\ Hospital, Cairo University, Giza, \\ Egypt; ${ }^{3}$ Department of Physiotherapy, \\ College of Medical and Health \\ Sciences, Ahlia University, Manama, \\ Kingdom of Bahrain; ${ }^{4}$ Department \\ of Physical Therapy for Internal \\ Medicine, Faculty of Physical Therapy, \\ Beni-Suef University, Beni-Suef, Egypt; \\ ${ }^{5}$ Department of Physiotherapy for \\ Womens Health, Faculty of Physical \\ Therapy, Cairo University, Giza, Egypt
}

Correspondence: Walid K Abdelbasset Department of Physical Therapy, Kasr Al-Aini Hospital, Cairo University, P.O. Box I 1562, Giza, Egypt

Tel +20 237154469

Email walidkamal.wr@gmail.com

\begin{abstract}
Background: It has been documented that aerobic exercise may increase pulmonary functions and aerobic capacity, but limited data has evaluated a child's satisfaction and pediatric quality of life (PQoL) with exercise training.
\end{abstract}

Objectives: This study aimed to investigate the effects of moderate-intensity exercise training on asthmatic school-aged children.

Subjects and methods: This study included 38 school-aged children with asthma ( 23 males and 15 females) aged between $8-12$ years. They were randomly assigned to two groups, aerobic exercise (AE) and conventional treatment (Con $\mathrm{ttt}$ ) groups. The $\mathrm{AE}$ group received a program of moderateintensity aerobic exercise for 10 weeks with asthma medications and the Con $t t$ group received only asthma medications without exercise intervention. A home respiratory exercise was recommended for the two groups. Aerobic capacity was investigated using maximal oxygen uptake $\left(\mathrm{VO}_{2 \max }\right), 6$-minute walk test (6MWT), and fatigue index. PQoL was evaluated using Pediatric Quality of Life Questionnaire (PQoLQ). Also, pulmonary function tests were performed, and the results recorded.

Results: The findings of this study showed significant improvements in pulmonary functions and $\mathrm{VO}_{2 \max }$ in the two groups; however, this improvement was significantly higher in the $\mathrm{AE}$ group than in the Con ttt group $(p<0.05)$. The 6MWT and fatigue index improved in the AE group ( $p<0.05)$ but not in the Con ttt group $(p>0.05)$. All dimensions of PQoL significantly improved in the AE group $(p<0.05)$, but there was no significant improvement in the Con ttt group after the 10-week intervention period ( $p>0.05)$.

Conclusion: Ten weeks of physical exercise had beneficial effects on pulmonary functions, aerobic capacity, and PQoL in school-aged children with asthma. Effort and awareness should be dedicated to encouraging the active lifestyle among different populations, especially asthmatic children.

Keywords: asthma, pediatrics, maximum oxygen uptake, exercise-induced bronchoconstriction, moderate-intensity exercise

\section{Background}

Asthma is a common cause of chronic disorder and disability in pediatric population. It is considered to have a negative impact on the daily life activity of children, leading to exercise limitations. Asthmatic children, especially those suffering from limited disease control, show lesser activity than normal children. ${ }^{1,2}$

Children with asthma are inclined to have an inactive lifestyle when compared to healthy children. During exercise, they exhibit low endurance resulting from shortness 
of breath, termed as exercise-induced bronchoconstriction, and activity barriers according to healthy recommendation and advise. ${ }^{3}$

Less aerobic capacity and asthma are manifested by difficulty in breathing, wheezing, and coughing, which in turn affect a child physically, socially, educationally, and emotionally. ${ }^{4}$

Health-related quality of life (HRQoL) is lowered in asthmatic children when compared to their peers. ${ }^{5}$ Previous studies advocated that asthma can be controlled and managed by undergoing regular exercise training and participating in sport activities. ${ }^{6}$

Pulmonary rehabilitation has been highly recommended for chronic pulmonary diseases, particularly bronchial asthma in adult patients. The exercise intervention has been demonstrated to improve functional capacity, lower asthma symptoms, decrease health care resource utilization, and enhance HRQoL. ${ }^{7,8}$

In contrast, there have been few studies on rehabilitation in children suffering from chronic pulmonary diseases. These studies approved the positive influences of exercise on lung function and cardiopulmonary fitness, but data regarding the impacts of exercise training and physical activity on HRQoL in asthmatic school-aged children were poorly represented. ${ }^{6}$

Asthmatic children were instructed to receive physical exercise $^{9}$ and when asthma was controlled with medication, asthmatic children were able to carry out the physical exercise smoothly. ${ }^{10}$ The greater physical activity is related to the greater quality of life (QoL) and psychological function; the more it enhanced the aerobic capacity, the more was the reduction in morbidity rate..$^{9-11}$ Ninety percent of untreated asthmatic children would suffer from asthma symptoms during vigorous exercise, termed as exercise-induced bronchoconstriction. ${ }^{12}$

An improved cardiorespiratory fitness may have positive effects for asthmatic children by improving exercise capacity and tolerance, the outcome being inhibition of exercise-induced bronchoconstriction. ${ }^{13}$ The fitness level of exercise may be improved after exercise training in asthmatic children, ${ }^{1,9}$ an improvement in maximal oxygen uptake up to $20 \%$ was also noticed. ${ }^{14}$ But, according to the previous reports, different methods of exercise training, varying in duration, mood, frequency, and intensity of exercise, were adapted based on the severity level of asthma. ${ }^{15}$

Some intervention reports do not provide sufficient details about the exercise program, including types, intensity level, and structure of exercise. ${ }^{3,4}$ Some studies reported that children performed exercise program insufficiently. ${ }^{4,13,14}$ Only one study approved that children enjoyed exercise training, ${ }^{3}$ but there was no report on qualitative extensive examination combined with other physical measures.

Another study mentioned that the elucidation of shortness of breath throughout the physical exercise intervention has induced a risky manifestation of asthma, which may prevent children from exercise training. ${ }^{16}$ Previous studies have documented that aerobic exercise may increase pulmonary functions and aerobic capacity, but limited data have evaluated the child's satisfaction and pediatric quality of life (PQoL) with exercise training. ${ }^{8-11}$ The hypothesis of the current study was that 10 -week moderate-intensity aerobic exercise may improve pulmonary function, aerobic capacity, and HRQoL in asthmatic children.

\section{Objectives}

This study aimed to evaluate the effect of 10-week aerobic exercise on pulmonary functions, aerobic capacity, and PQoL in school-aged children with asthma.

\section{Subjects and methods Subjects}

Between June and September 2017, 38 asthmatic school-aged children between 8 and 12 years ( 23 males and 15 females) were recruited in this study. All children were referred by a chest physician to the outpatient Physical Therapy Department, Cairo University Children Hospital. All children were diagnosed with moderate persistent asthma (forced expiratory volume in 1 second $\left[\mathrm{FEV}_{1}\right]=60 \%-80 \%$ predicted); were receiving long-acting $\beta 2$-agonist and corticosteroid medications; and were suffering from dyspnea or wheezing, night cough, and airway obstruction in the last 6 months (based on pulmonary function tests). Thirty-eight children were randomly assigned to two groups with 19 children in each group. The first group received medical treatment with a program of moderate-intensity aerobic exercise three times/week for 10 weeks (aerobic exercise [AE] group), and the second group received only medical treatment without any exercise program (conventional treatment group [Con ttt]). All children of both groups were instructed to perform home breathing exercise. Any child that had post-bronchodilator $\mathrm{FEV}_{1}<60 \%$, a severe medical illness such as uncontrolled heart disease, neuromuscular limitations, orthopedic problems, and endocrine disorders were excluded from the study, as these conditions could affect their capacity to perform physical exercise. This study was approved by the ethical committee of Physical Therapy Department, Cairo University Children Hospital, Cairo University. Written informed 
consent was obtained from parents or caregivers of all the children who participated in the study.

\section{Randomization}

From among the 49 asthmatic children, 38 children participated in this study. Five children did not meet the inclusion criteria of the study, and six children declined to participate in the study without any registered cause. Randomization of 38 children was performed using sealed envelopes by an investigator who was not involved in the assessment, diagnosis, and treatment. The sealed envelopes contained an equal number of slips with either letter A or B indicating which child was in the study group or the control group. The letter A was assigned to $\mathrm{AE}$ group, and letter B was assigned to the Con ttt group. This allocation was performed before the initial assessment. The flow diagram showing the study protocol is presented in Figure 1.

\section{Instruments}

Body weight, height, and body mass index (BMI) were measured for all children using weight and height scale. Treadmill (RT-103i, Revo Fitness, Lahore, Pakistan) was used for warming up exercise and measuring maximal oxygen uptake $\left(\mathrm{VO}_{2 \max }\right)$; pulmonary functions were measured using a digital spirometer (Contec: SP10; Contec Medical Systems Co., Hebei Province, China); and child's QoL and asthma control in asthmatic children were evaluated using Pediatric Quality of Life Questionnaire (PQoLQ).

\section{Procedure}

\section{Baseline evaluation}

All children were evaluated for the pulmonary functions (forced vital capacity $[\mathrm{FVC}], \mathrm{FEV}_{1}$ ), aerobic capacity $\left(\mathrm{VO}_{2 \max }, 6\right.$-minute walk test [6MWT], and fatigue index), and PQoL before the intervention (pre-program) and at the end of 10 weeks of intervention (post-program) by the previous investigator who was blinded concerning the group to which each patient was appointed.

At the commencement of the study, all children were instructed about the methods, procedure, and benefits of the study. Randomly, the children were assigned to two groups, with 19 children in each group. AE group (Group I) received a program of moderate-intensity aerobic exercise three times/ week for 10 weeks in addition to asthma medications (combination of long-acting $\beta 2$-agonists and corticosteroids), and Con ttt group (Group II) received only medications of asthma without any exercise program. Chest X-ray evaluation was carried out for all children regularly in the department of radiology and was abided by a pulmonologist to assess any lung abnormalities during the study period after their parental consent. The results of pulmonary functions, aerobic capacity, and PQoL were recorded at the beginning and at the end of the study.

\section{Intervention}

In the AE group, each child participated in the moderateintensity aerobic exercise program (exercise training at

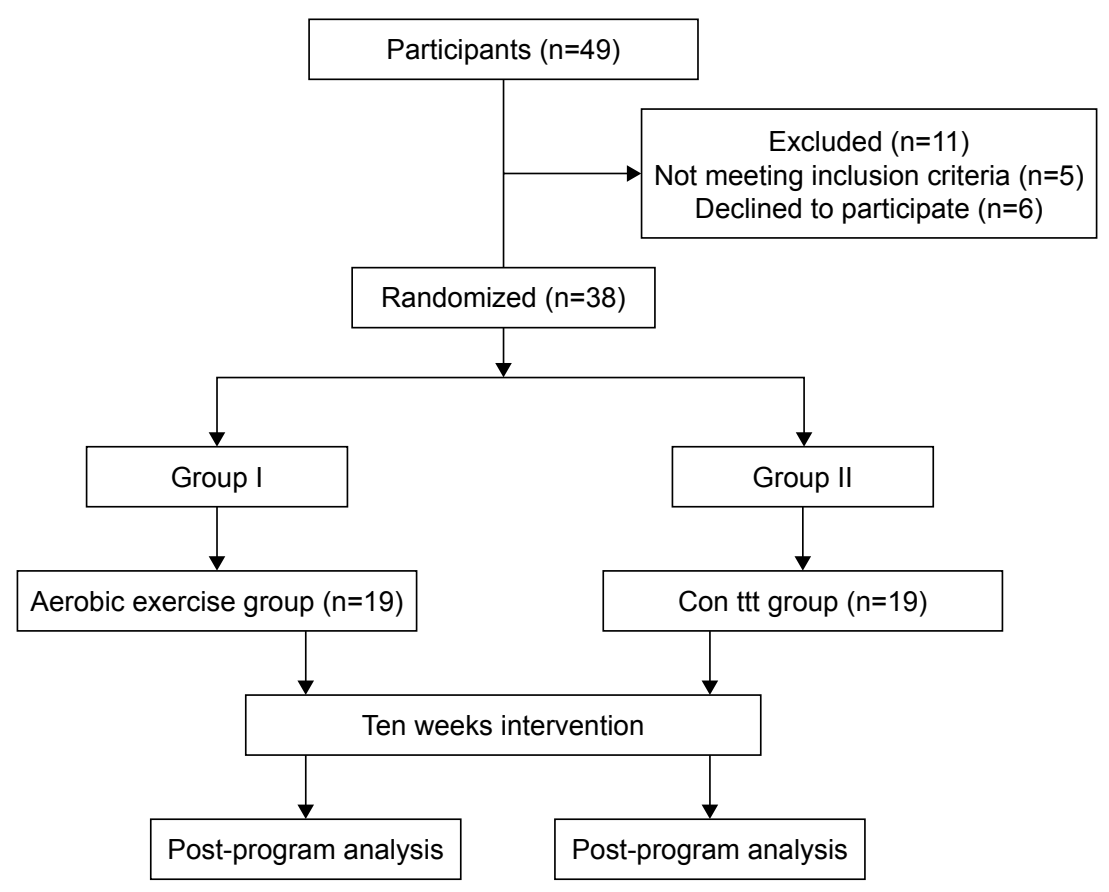

Figure I Flow diagram showing participants in the study. 
$50 \%-70 \%$ of the maximum heart rate $\left.\left[\mathrm{HR}_{\max }\right]\right)$ for 10 weeks, three times per week, with each exercise session lasting for 40 minutes in the morning. Each child was instructed to inhale a bronchodilator before the exercise session and not to eat for 2 hours before the exercise session to avoid exerciseinduced airway obstruction.

The exercise training program was in the form of walking on a treadmill with firmly grasping the rails to maintain balance, after the child had been accustomed to walk on the treadmill. The exercise session started with a 5-minute warm up which involved walking with no resistance and no inclination at the walkway of treadmill, followed by 30 minutes of walking with 5 degrees inclination at the walkway of the treadmill and adjusted speed to reach $50 \%-60 \%$ of the $\mathrm{HR}_{\max }$ in the first 5 weeks of the study. Then the inclination was increased to 10 degrees and the speed was increased up to $60 \%-70 \% \mathrm{HR}_{\max }$ in the second 5 weeks of the study. The session ended with 5 minutes of recovery in which the intensity of the exercise was reduced to the level of the warm up.

All the children of the two groups were instructed to receive asthma medications regularly. Home breathing exercise was recommended for both groups: study and control groups.

\section{Final evaluation}

After the 10-week intervention period, pulmonary functions, aerobic capacity, and PQoLQ were reassessed in the AE and Con ttt groups.

\section{Sample size}

Sample size for this study was calculated using the $\mathrm{VO}_{2 \max }$ measure. A previous study has approved that the aerobic exercise showed a significant mean difference in $\mathrm{VO}_{2 \max }$ measure $(5.3 \mathrm{~mL} / \mathrm{kg} / \mathrm{min})$ with standard deviation $(4.5 \mathrm{~mL} / \mathrm{kg} / \mathrm{min}){ }^{2}$ According to this difference and ability to achieve a power of $80 \%(\alpha=0.05)$ our study required 16 children in each group. A dropout rate of $20 \%$ was assumed in the study; therefore, 19 children were recruited in each group to ensure that at least 16 children completed the study.

\section{Data analysis}

Descriptive statistics were applied in mean and standard deviation form. The normality of the data was tested using the Kolmogorov-Smirnov test. Inferential statistics assessed alterations of all measurements using unpaired $t$-test between $\mathrm{AE}$ and Con $\mathrm{ttt}$ groups, and paired $t$-test was applied to measure changes within the group. SPSS version 20.0 (SPSS, Chicago, IL, USA) was used for data analysis with a significance level of $p<0.05$ for all statistical measurements.

\section{Results \\ Baseline characteristics}

As demonstrated in Table 1, there were no significant differences between the $\mathrm{AE}$ and Con ttt groups at the beginning of the study in regard to their gender, age, BMI, FVC, $\mathrm{FEV}_{1}$, $\mathrm{VO}_{2 \max }, 6 \mathrm{MWT}$, fatigue index, and PQoLQ $(p>0.05)$.

\section{Pulmonary functions}

There was no significant difference in $\mathrm{FVC}$ and $\mathrm{FEV}_{1}$ between the two groups before the intervention $(p>0.05)$, as presented in Table 2. However, the post-treatment outcomes showed significant differences in favor of the AE group $(p<0.05)$, as presented in Table 2. Comparison of the preand post-treatment mean values of the pulmonary functions in both $\mathrm{AE}$ and Con ttt groups reported significant changes $(p<0.05)$, as presented in Table 3 .

\section{Aerobic capacity}

As demonstrated in Table 1, comparison of the mean pretreatment values of $\mathrm{VO}_{2 \max }, 6 \mathrm{MWT}$, and fatigue index between aerobic and conventional groups indicated nonsignificant differences $(p>0.05)$. At the end of the study, the two groups showed significant improvement in $\mathrm{VO}_{2 \max }$ $(p<0.05)$, as presented in Table 2. Comparison of the pre- and post-treatment mean values of $\mathrm{VO}_{2 \max }$ indicated

Table I Baseline characteristics of all children participating in this study

\begin{tabular}{|c|c|c|c|}
\hline Variables & $\begin{array}{l}\text { AE group } \\
(n=19)\end{array}$ & $\begin{array}{l}\text { Con group } \\
(n=19)\end{array}$ & $p$-value \\
\hline \multicolumn{4}{|l|}{ Gender, n (\%) } \\
\hline Male & $12(63.2)$ & II (57.9) & 0.6842 \\
\hline Female & $7(36.8)$ & $8(42.1)$ & \\
\hline Age (years) & $9.84 \pm I .76$ & $10.04 \pm 1.52$ & 0.7100 \\
\hline Height (cm) & $136.3 \pm 9.6$ & $134.4 \pm 10.8$ & 0.5701 \\
\hline Weight (kg) & $39.4 \pm 7.6$ & $40.2 \pm 7.2$ & 0.7410 \\
\hline BMI $\left(\mathrm{kg} / \mathrm{m}^{2}\right)$ & $21.3 \pm 3.02$ & $22.13 \pm 4.1$ & 0.4820 \\
\hline FEV,$\% p r e d$ & $7 I \pm 8.2$ & $70.3 \pm 9.1$ & 0.8047 \\
\hline FVC \%pred & $79.4 \pm 11.4$ & $78.6 \pm 12.2$ & 0.8357 \\
\hline \multicolumn{4}{|l|}{ Aerobic capacity } \\
\hline $\mathrm{VO}_{2 \max }(\mathrm{mL} / \mathrm{kg} / \mathrm{min})$ & $39.72 \pm 6.18$ & $40.09 \pm 5.45$ & 0.8459 \\
\hline 6MWT $(\mathrm{m})$ & $452.64 \pm 43.26$ & $478.5 \mathrm{I} \pm 49.17$ & 0.0937 \\
\hline Fatigue index & $548.21 \pm \mid 31.72$ & $573.42 \pm 136.67$ & 0.5662 \\
\hline \multicolumn{4}{|l|}{ PAQLQ scores } \\
\hline Overall PQoL & $5.2 \pm 1.2$ & $5.3 \pm 0.91$ & 0.7739 \\
\hline Activity scores & $4.8 \pm 0.74$ & $4.9 \pm 0.65$ & 0.6607 \\
\hline Symptom scores & $4.5 \pm 0.62$ & $4.6 \pm 0.83$ & 0.6764 \\
\hline Emotion scores & $5.5 \pm 0.68$ & $5.7 \pm 0.79$ & 0.4085 \\
\hline
\end{tabular}

Notes: Significant at $p<0.05$. Data presented as mean \pm SD.

Abbreviations: $\mathrm{AE}$, aerobic exercise; Con, conventional; BMI, body mass index; FVC, forced vital capacity; $\mathrm{FEV}_{1}$, forced expiratory volume in I second; $\mathrm{VO}_{2 \max }$, maximal oxygen uptake; 6MWT, 6-minute walk test; PAQLQ, Pediatric Asthma Quality of Life Questionnaire; PQoL, pediatric quality of life. 
Table 2 Pre- and post-treatment mean differences of BMI, lung functions, aerobic capacity, and HRQoL within each group

\begin{tabular}{|c|c|c|c|c|c|c|}
\hline \multirow[t]{2}{*}{ Variables } & \multicolumn{3}{|l|}{ AE group } & \multicolumn{3}{|l|}{ Con group } \\
\hline & Pre & Post & p-value & Pre & Post & $p$-value \\
\hline BMI $\left(\mathrm{kg} / \mathrm{m}^{2}\right)$ & $21.3 \pm 3.02$ & $20.1 \pm 2.82$ & 0.214 & $22.13 \pm 4.1$ & $22.21 \pm 4.6$ & 0.955 \\
\hline \multicolumn{7}{|l|}{ Lung functions } \\
\hline FEV, \%pred & $71 \pm 8.2$ & $83.6 \pm 5.3$ & $0.001 *$ & $70.3 \pm 9.1$ & $75.9 \pm 7.6$ & $0.047^{*}$ \\
\hline FVC \%pred & $79.4 \pm 11.4$ & $94.7 \pm 8.5$ & $0.001 *$ & $78.6 \pm 12.2$ & $86.1 \pm 9.5$ & $0.04 I^{*}$ \\
\hline \multicolumn{7}{|l|}{ Aerobic capacity } \\
\hline $\mathrm{VO}_{2 \max }(\mathrm{mL} / \mathrm{kg} / \mathrm{min})$ & $39.72 \pm 6.18$ & $59.8 \pm 4.7$ & $0.001 *$ & $40.09 \pm 5.45$ & $48.7 \pm 6.5$ & $0.01 I^{*}$ \\
\hline $6 \mathrm{MWT}(\mathrm{m})$ & $452.64 \pm 43.26$ & $673.25 \pm 75.37$ & $0.001 *$ & $478.5 I \pm 49.17$ & $513.42 \pm 67.56$ & 0.077 \\
\hline Fatigue index & $548.21 \pm 131.72$ & $451.82 \pm 118.7$ & $0.023^{*}$ & $573.42 \pm 136.67$ & $687.54 \pm 160.38$ & 0.063 \\
\hline \multicolumn{7}{|l|}{ PAQLQ } \\
\hline Overall PQoL & $5.2 \pm 1.2$ & $7.4 \pm 1.6$ & $0.00 I^{*}$ & $5.3 \pm 0.91$ & $5.8 \pm 1.32$ & 0.182 \\
\hline Activity scores & $4.8 \pm 0.74$ & $6.9 \pm 1.2$ & $0.001 *$ & $4.9 \pm 0.65$ & $5.1 \pm 1.21$ & 0.529 \\
\hline Symptom scores & $4.5 \pm 0.62$ & $6.4 \pm 0.53$ & $0.001 *$ & $4.6 \pm 0.83$ & $4.8 \pm 1.52$ & 0.618 \\
\hline Emotion scores & $5.5 \pm 0.68$ & $7.6 \pm 0.57$ & $0.001 *$ & $5.7 \pm 0.79$ & $5.9 \pm 1.23$ & 0.554 \\
\hline
\end{tabular}

Note: *Significant at $p<0.05$.

Abbreviations: $\mathrm{AE}$, aerobic exercise; Con, conventional; BMI, body mass index; FVC, forced vital capacity; $\mathrm{FEV}_{1}$, forced expiratory volume in I second; VO ${ }_{2 m a x}$, maximal oxygen uptake; 6MWT, 6-minute walk test; PAQLQ, Pediatric Asthma Quality of Life Questionnaire; PQoL, pediatric quality of life; HRQoL, health-related quality of life.

significant differences between the aerobic and conventional groups $(p<0.05)$ in favor of the AE group. On the other hand, the $6 \mathrm{MWT}$ and fatigue index improved significantly in the AE group $(p<0.05)$ when compared to the Con ttt group $(p>0.05)$ at the end of the study. Comparing of the preand post-treatment mean values of the 6MWT and fatigue index indicated significant differences between the aerobic and conventional groups $(p<0.05)$ in favor of the aerobic exercise program, as presented in Table 3.

\section{Pediatric Quality of Life Questionnaire}

As demonstrated in Table 3, comparison of the mean pretreatment values of overall QoL, activities, symptoms, and emotion scores between both groups indicated nonsignificant differences $(p>0.05)$. In addition, the post-treatment comparison indicated significant differences of all finding measures in favor of the study group $(p<0.05)$. As demonstrated in Table 2, comparison of the pre- and post-treatment mean values of overall QoL, activities, symptoms, and emotion scores indicated significant differences in the AE group $(p<0.05)$. But, the Con ttt group showed nonsignificant improvement in all dimensions of $\mathrm{PQoL}$ at the end of the study period $(p>0.05)$.

\section{Attendance rate}

In this study, there was a high rate of satisfaction and fun among the children, which was evident by the rate of attendance which was $97.7 \%$. Thirteen children regularly attended

Table 3 Mean differences of BMI, lung functions, aerobic capacity, and HRQoL between the two groups pre- and post-treatment

\begin{tabular}{|c|c|c|c|c|c|c|}
\hline \multirow[t]{2}{*}{ Variables } & \multicolumn{3}{|c|}{ Pre-treatment } & \multicolumn{3}{|l|}{ Post-treatment } \\
\hline & AE group & Con group & $p$-value & AE group & Con group & $p$-value \\
\hline $\mathrm{BMI}\left(\mathrm{kg} / \mathrm{m}^{2}\right)$ & $21.3 \pm 3.02$ & $22.13 \pm 4.1$ & 0.4820 & $20.1 \pm 2.52$ & $22.21 \pm 4.6$ & 0.088 \\
\hline \multicolumn{7}{|l|}{ Lung functions } \\
\hline FEV, \%pred & $7 I \pm 8.2$ & $70.3 \pm 9.1$ & 0.8047 & $83.6 \pm 5.3^{*}$ & $75.9 \pm 7.6^{*}$ & 0.002 \\
\hline FVC \%pred & $79.4 \pm I I .4$ & $78.6 \pm 12.2$ & 0.8357 & $94.7 \pm 8.5^{*}$ & $86.1 \pm 9.5^{*}$ & 0.006 \\
\hline \multicolumn{7}{|l|}{ Aerobic capacity } \\
\hline $\mathrm{VO}_{2 \max }(\mathrm{mL} / \mathrm{kg} / \mathrm{min})$ & $39.72 \pm 6.18$ & $40.09 \pm 5.45$ & 0.8459 & $59.8 \pm 4.7^{*}$ & $48.7 \pm 6.5^{*}$ & 0.001 \\
\hline 6 MWT $(\mathrm{m})$ & $452.64 \pm 43.26$ & $478.5 I \pm 49.17$ & 0.0937 & $673.25 \pm 75.37 *$ & $513.42 \pm 67.56$ & 0.001 \\
\hline Fatigue index & $548.21 \pm 131.72$ & $573.42 \pm 136.67$ & 0.5662 & $451.82 \pm 118.72^{*}$ & $687.54 \pm 160.38$ & 0.001 \\
\hline \multicolumn{7}{|l|}{ PAQLQ } \\
\hline Overall PQoL & $5.2 \pm 1.2$ & $5.3 \pm 0.91$ & 0.7739 & $7.4 \pm 1.6^{*}$ & $5.8 \pm 1.32$ & 0.018 \\
\hline Activity scores & $4.8 \pm 0.74$ & $4.9 \pm 0.65$ & 0.6607 & $6.9 \pm 1.2 *$ & $5.1 \pm I .2 I$ & 0.001 \\
\hline Symptom scores & $4.5 \pm 0.62$ & $4.6 \pm 0.83$ & 0.6764 & $6.4 \pm 0.53 *$ & $4.8 \pm 1.52$ & 0.001 \\
\hline Emotion scores & $5.5 \pm 0.68$ & $5.7 \pm 0.79$ & 0.4085 & $7.6 \pm 0.57 *$ & $5.9 \pm 1.23$ & 0.001 \\
\hline
\end{tabular}

Note: *Significant at $p<0.05$.

Abbreviations: $\mathrm{AE}$, aerobic exercise; Con, conventional; $\mathrm{BMI}$, body mass index; FVC, forced vital capacity; $\mathrm{FEV}_{1}$, forced expiratory volume in I second; $\mathrm{O}_{2 \text { max }}$, maximal oxygen uptake; 6MWT, 6-minute walk test; PAQLQ, Pediatric Asthma Quality of Life Questionnaire; PQoL, pediatric quality of life; HRQoL, health-related quality of life. 
30 sessions of the intervention program. Two children did not attend three sessions, three children did not attend two sessions, and one child missed only one session.

\section{Gender differences}

As demonstrated in Table 4, there were nonsignificant differences between males and females at the beginning of the study within each group. After 10-week intervention, the AE group showed significant improvements in all variables in both genders with nonsignificant differences between the two genders. While the Con ttt group showed significant improvement in $\mathrm{FEV}_{1}, \mathrm{FVC}$, and $\mathrm{VO}_{2 \max }$ in the two genders, there were nonsignificant differences in fatigue index, 6MWT, and all dimensions of PQoL in the two genders. Also, the mean post-treatment values of all variables indicated nonsignificant differences between males and females within each group $(p>0.05)$.

\section{Discussion}

The major findings of this study showed that asthmatic children participating in aerobic exercise training showed improved pulmonary functions, aerobic capacity, and PQoL. These findings were obtained through a program involving moderate-intensity exercise. The asthmatic children had a satisfied participating program without asthma restrictions or attacks, and they discerned that their pulmonary functions and aerobic capacity had increased. Also, PQoL had improved post-treatment compared with pre-treatment record. The children who participated in the aerobic exercise program appreciated being acknowledged as competent, and the treatment was nominated considering any child having asthma is a normal. The examiners confirmed that the exercise was moderate intensity and approved satisfaction while joining the exercise that it was comfortable and easy to perform; they also confirmed equitable competition and used satisfactions to participate in the exercise program.

Many previous studies investigated the effect of exercise in asthmatic children with different exercise modes including running, ${ }^{13,17}$ cycling, ${ }^{18,19}$ and swimming, ${ }^{14,20}$ which were highly applied regularly. These studies did not determine whether the children were feeling satisfied and experiencing fun within these exercise programs or which interactions the children felt most pleasurable. The current study assessed the child's satisfaction and enjoyment.

This study presumes that the fulfillment and pleasure experienced by the children inspired them to participate in the moderate-intensity aerobic exercise and contributed to the high attendance during these training sessions. Previously, only two studies determined the perspectives of children during

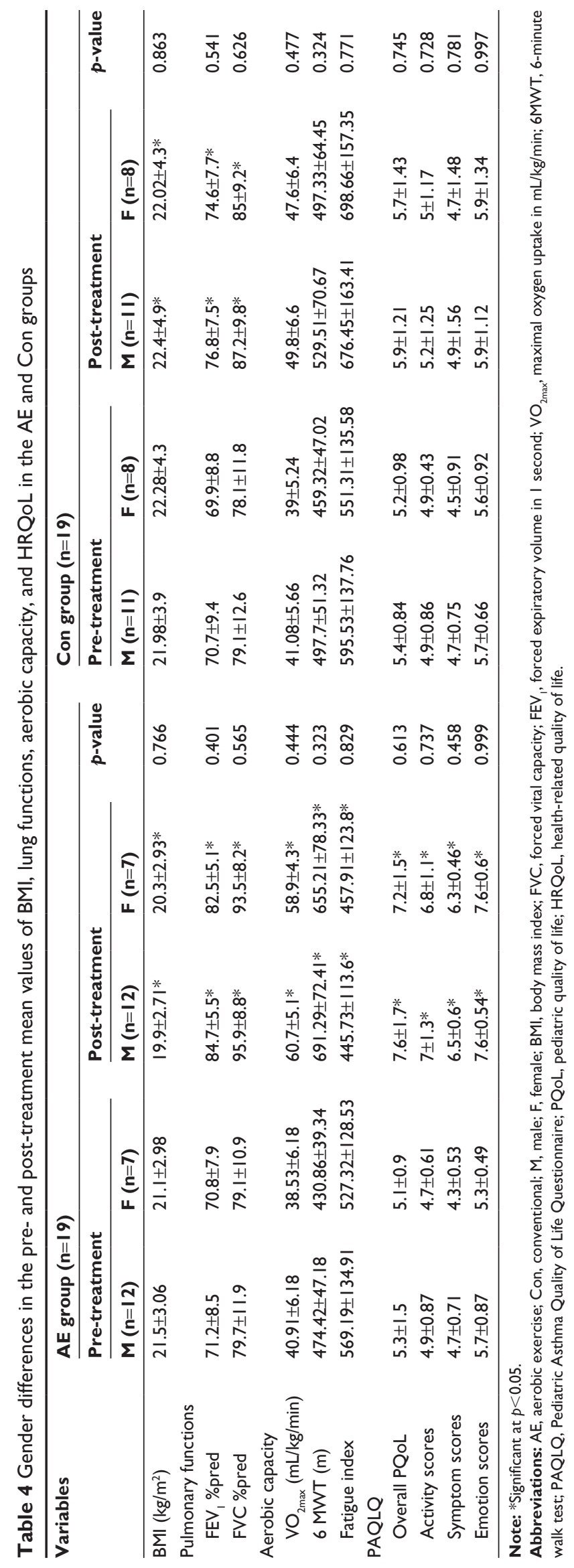


an exercise program. One study showed that the children's fulfillment and enjoyment inspired them to participate in an exercise intervention at a high intensity, contributing to the high attendance rate and no absences during exercise training intervention. ${ }^{1}$ Second study explained that the perception of children showed the heightened capability to control asthma throughout the exercise intervention. ${ }^{11}$ Unfortunately, the exercise types and devotion have not been clarified.

The attendance rates and absence during an exercise program may indicate that the children are motivated and in favor of participating in different exercise modes. In asthmatic children interventions, absence rates of $22 \%$ in the 6-week individuated cycle Ergometer training ${ }^{19}$ and $13 \%$ in the 4 -month running training program ${ }^{17}$ have been informed.

Lower drop-out rates were mentioned in a 3 month program of frequent exercise training with various activities in the indoor rehabilitation gym and home program about $4 \%$ and decreased $3 \%$ in eight-week training basketball program. ${ }^{4}$ These two studies did not mention the causes of absence, however, it was concluded that these studies involved mutual patient support. Peer support has been exhibited to be related to the high-intensity physical exercise regardless asthma. ${ }^{21}$

According to the current study results, the rate of attendance was very high (97.7\%) during the study program. Similar results were reported in the previous studies ${ }^{1,22}$ that reported highest attendance rate in the active play program. The intervention program conducted training sessions in nearby areas, which might have contributed to increased attendance rate. ${ }^{22}$ Also, a study including a small sample size would ensure that all the participants attended the intervention session, when compared to the studies which included a large number of patients. ${ }^{1}$ In the present study, the participants' home was close to the study place and also, a small number of study participants had led to an increase in the rate of attendance. On the other hand, a previous study reported the attendance rate of $68 \%$ in their study, which evaluated the effects of running exercise on 10 asthmatic children. Asthmatic children may feel running exercise with various interventions as fun when compared with indoor training, performed in the present study. ${ }^{23}$ A review study reported that intensity was the most prominent factor than the mode of aerobic exercise for increasing aerobic capacity after an exercise training. ${ }^{9}$

In one study, children's reports revealed that aerobic exercise and satisfaction are vital in improving the activity and adequate intensity. In healthy children, high-intensity anaerobic exercise caused higher enhancements in aerobic capacity than low-intensity exercise. ${ }^{24}$
In the current study, asthmatic children received moderate-intensity aerobic exercise $\left(70 \% \mathrm{HR}_{\max }\right)$. Generally, the intensity of exercise has been lowered during each session as the short active periods is required to recognize the exercise program, including adapting and fitting the monitors of heart rate. Aerobic capacity improved significantly in the AE group than in the Con $\mathrm{ttt}$ group after the intervention program when compared with the baseline measurements. The fatigue index was reduced in the AE group and increased in the Con ttt group, but the changes were nonsignificant, which could be ascribed to improvement in respiratory muscle strength. Our study provided an explanation for the increased capability of managing aerobic exercise, as well as improved discerned ability or increased feeling of competence.

The consequence of perceived ability and normality for the asthmatic children and the fitting of children to sociable standards is advantageously reported. ${ }^{25}$ This study showed that examiners can produce satisfaction, fun, and extreme aerobic capacity with great attendance rate by concentrating on self-reliance and normality of children, and by enhancing, clarifying, and identifying all social standards in the children's study. It might be to suggest that the examiners role and the aerobic exercise program are just as important as the clinical organization comprising of planning, scheduling, guiding, and designing the exercise. Previous studies have indicated that incentive and obligation in exercise training were dependent on guidance; the construction provided; and the fundamental psychological requirement for independence, connectedness, and capability. ${ }^{26}$

The present study design of moderate-intensity aerobic exercise appeared to improve expertise, satisfaction, and enjoyment together with the examiner's discussion on the establishment of equitable contest and focus on expertise, fun, society, and handling the children that are well qualified. The findings of the restrictions induced by asthma away from the treatment scene and the children's desire to be normal despite having asthma may suggest the experiences and interaction within the exercise program. The examiners' deliberate emphasis on treating asthmatic children as normal competent subjects may thus have appeared to these asthmatics as motivating them to exercise and enjoy the exercise training despite the obvious presence of asthma. Physical exercise barriers may be encountered either due to physiological restrictions resulting from a disorder or due to pitiable psychological adaptation to the disorder. ${ }^{10}$

The outcomes of the current study show that the restrictions of physical exercise depend on the situation and may change with the social background. Asthmatic children may endure aggravation, confusion, and less self-trust resulting 
from disease-related restrictions. ${ }^{25,27}$ Asthmatic children may leave physical exercise training due to the fear of parents and defensiveness. ${ }^{16}$ In the current study, participants appeared to overcome those obstacles and restrictions, and the parents or caregivers provided the children independence by staying away during the aerobic exercise sessions.

The reports of children experiencing reported enhancements in aerobic capacity and exercise tolerance, contentment, and manifestations of asthma, emphasize the positive effects of producing various social conditions and standards for treatment of asthmatic children. Furthermore, the child's improvement of $\mathrm{VO}_{2 \max }, 6 \mathrm{MWT}$, and especially QoL, support the possibility that the treatment program can cause change in children with increased age, partake in low initiated aerobic exercise by themselves, and have a lowered QoL compared with conventional group. ${ }^{28}$

The current treatment may be perceived as a required resource. Nevertheless, aerobic exercise is related to many beneficial findings in asthma sufferers ${ }^{11}$ and can result in savings of expenses related to mortality and morbidity, while aiding in reduction of good-health expense disbursements, which cost from $1 \%$ to $2 \%$ of total health care expenses in developed countries. ${ }^{29}$

\section{Conclusion}

According to the study findings, improving the level of physical activity among the asthmatic children has a positive effect on the pulmonary functions, aerobic capacity, and PQoL. Effort and awareness should be dedicated to encouraging the active lifestyle among different populations, especially asthmatic children.

\section{Acknowledgment}

The authors would like to thank the parents for allowing their children to participate in the study.

\section{Disclosure}

The authors report no conflicts of interest in this work.

\section{References}

1. Westergren T, Fegran L, Nilsen T, Haraldstad K, Kittang OB, Berntsen S. Active play exercise intervention in children with asthma: a pilot study. BMJ Open. 2016;6:e009721.

2. Meyer A, Gunther S, Volmer T, Taube K, Baumann HJ. A 12-month, moderate intensity training program improves fitness and quality of life in adult with asthma: a controlled trial. BMC Pulm Med. 2015;15:56.

3. van Veldhoven NH, Vermeer A, Bogaard JM, et al. Children with asthma and physical exercise: effects of an exercise program. Clin Rehab. 2001;15: 360-370.

4. Basaran S, Guler-Uysal F, Ergen N. Effects of physical exercise capacity and pulmonary function in children with asthma. J Rehab Med. 2006;38:130-135.
5. Juniper EF. How important is quality of life in pediatric asthma? Pediatr Pulmonol. 1997;15:17-21.

6. Ram FS, Robinson RM, Black PN. Effects of physical training in asthma: a systematic review. Br J Sports Med. 2000;34:162-167.

7. Cooper CB. Exercise in chronic pulmonary disease: limitations and rehabilitation. Med Sci Sports Exer. 2001;33:S643-S646.

8. BTS Statement. Pulmonary rehabilitation. Thorax. 2001;56:827-834.

9. Crosbie A. The effect of physical training in children with asthma on pulmonary function, aerobic capacity and health-related quality of life: a systematic review of randomized control trials. Pediatr Exerc Sci. 2012;24:472-489.

10. Mosquera RA, Samuels C, Flores G. Family language barriers and special-needs children. Pediatrics. 2016;138:e20160321.

11. Carson KV, Chandratilleke MG, Picot J, Brinn MP, Esterman AJ, Smith PJ. Physical training for asthma. Cochrane Database Syst Rev. 2013;9:1-71.

12. McFadden ER Jr, Gilbert IA. Exercise-induced asthma. N Engl J Med. 1994;330:1362-1367.

13. Varray AL, Mercier JG, Prefaut CG. Individualized training reduces excessive exercise hyperventilation in asthmatics. Int $J$ Rehabil Res. 1995;18:297-312.

14. Varray AL, Mercier JG, Terral CM, Prefaut CG. Individualized aerobic and high intensity training for asthmatic children in an exercise readaptation program: is training always helpful for better adaptation to exercise? Chest. 1991;99:579-586.

15. Wanrooij VH, Willeboordse M, Dompeling E, van de Kant KDG. Exercise training in children with asthma: a systematic review. $\mathrm{Br} J$ Sports Med. 2014;48:1024-1031.

16. Williams B, Hoskins G, Pow J, Neville R, Mukhopadhyay S, Coyle J. Low exercise among children with asthma: a culture of over protection? A qualitative study of experiences and beliefs. Br J Gen Pract. 2010;60(577):e319-e326.

17. Orenstein DM, Reed ME, Grogan FT Jr, Crawford LV. Exercise conditioning in children with asthma. J Pediatr. 1985;106:556-560.

18. Fanelli A, Cabral AL, Neder JA, Martins MA, Carvalho CR. Exercise training on disease control and quality of life in asthmatic children. Med Sci Sports Exerc. 2007;39:1474-1480.

19. Counil FP, Varray A, Matecki S, et al. Training of aerobic and anaerobic fitness in children with asthma. J Pediatr. 2003;142:179-184.

20. Matsumoto I, Araki H, Tsuda K, et al. Effects of swimming training on aerobic capacity and exercise induced bronchoconstriction in children with bronchial asthma. Thorax. 1999;54:196-201.

21. Gomes EL, Carvalho CR, Peixoto-Souza FS, et al. Active video game exercise training improves the clinical control of asthma in children: randomized controlled trial. PLoS One. 2015;10:e135433.

22. Graff-Lonnevig V, Bevegard S, Eriksson BO, Kraepelien S, Saltin B. Two years' follow-up of asthmatic boys participating in a physical activity programme. Acta Paediatr Scand. 1980;69:347-352.

23. Fitch KD, Blitvich JD, Morton AR. The effect of running training on exercise-induced asthma. Ann Allergy. 1986;57:90-94.

24. Baquet G, van Praagh E, Berthoin S. Endurance training and aerobic fitness in young people. Sports Med. 2003;33:1127-1143.

25. Protudjer JL, Kozyrskyj AL, Becker AB, Marchessault G. Normalization strategies of children with asthma. Qual Health Res. 2009:19: 94-104.

26. Curran T, Hill AP, Niemiec CP. A conditional process model of children's behavioral engagement and behavioral disaffection in sport based on self-determination theory. J Sport Exerc Psychol. 2013;35:30-43.

27. Grover C, Armour C, Van Asperen PP, Moles RJ, Saini B. Medication use in Australian children with asthma: user's perspective. J Asthma. 2013;50: 231241.

28. Pawlowski CS, Thomsen TT, Schipperijn J, Troelsen J. Barriers for recess physical activity: a gender specific qualitative focus group exploration. BMC Public Health. 2014;14:639-648.

29. Turner S. Predicting and reducing risk of exacerbations in children with asthma in the primary care setting: current perspectives. Pragmat Obs Res. 2016;7:33-39. 
Patient Preference and Adherence

Dovepress

\section{Publish your work in this journal}

Patient Preference and Adherence is an international, peer-reviewed, open access journal that focuses on the growing importance of patient preference and adherence throughout the therapeutic continuum. Patient satisfaction, acceptability, quality of life, compliance, persistence and their role in developing new therapeutic modalities and compounds to optimize

Submit your manuscript here: http://www.dovepress.com/patient-preference-and-acherence-journa clinical outcomes for existing disease states are major areas of interest for the journal. This journal has been accepted for indexing on PubMed Central. The manuscript management system is completely online and includes a very quick and fair peer-review system, which is all easy to use. Visit http://www. dovepress.com/testimonials.php to read real quotes from published authors. 